\title{
Gastrointestinal symptoms as an extended clinical feature of Pierson syndrome: a case report and review of the literature
}

\author{
Kei Nishiyama', Mari Kurokawa', Michiko Torio', Yasunari Sakai ${ }^{1 *}$, Mitsuru Arima², Shoko Tsukamoto², \\ Satoshi Obata ${ }^{3}$, Shogo Minamikawa ${ }^{4}$, Kandai Nozu4 ${ }^{4}$, Noriyuki Kaku ${ }^{1,5}$, Yoshihiko Maehara ${ }^{5}$, Koh-Hei Sonoda ${ }^{2}$, \\ Tomoaki Taguchi ${ }^{3,5}$ and Shouichi Ohga ${ }^{1}$
}

\begin{abstract}
Background: Pierson syndrome (PS) is a rare autosomal recessive disorder, characterized by congenital nephrotic syndrome and microcoria. Advances in renal replacement therapies have extended the lifespan of patients, whereas the full clinical spectrum of PS in infancy and beyond remains elusive.

Case presentation: We present the case of a 12-month-old boy with PS, manifesting as the bilateral microcoria and congenital nephrotic syndrome. He was born without asphyxia, and was neurologically intact from birth through the neonatal period. Generalized muscle weakness and hypotonia were recognized from 3 months of age. The infant showed recurrent vomiting at age 5 months of age, and was diagnosed with gastroesophageal reflux and intestinal malrotation. Despite the successful surgical treatment, vomiting persisted and led to severely impaired growth. Tulobuterol treatment was effective in reducing the frequency of vomiting. Targeted sequencing confirmed that he had a compound heterozygous mutation in LAMB2 (NM_002292.3: p.Arg550X and p.Glu1507X). A search of the relevant literature identified 19 patients with severe neuro-muscular phenotypes. Among these, only 8 survived the first 12 months of life, and one had feeding difficulty with similar gastrointestinal problems.
\end{abstract}

Conclusions: This report demonstrated that severe neurological deficits and gastrointestinal dysfunction may emerge in PS patients after the first few months of life.

Keywords: Pierson syndrome, The laminin $\beta 2$ gene (LAMB2), Microcoria, Neurological signs, intestinal malrotation, Autonomic dysfunction

\section{Background}

Pierson syndrome (PS) is a rare autosomal recessive disorder, characterized by congenital nephrotic syndrome and microcoria [1]. These phenotypes are caused by the mutations of $L A M B 2$, which encodes laminin $\beta 2$ [2]. Among various isoforms, Laminin-521 is known to be the most common isoform containing the $\beta 2$ subunit

\footnotetext{
*Correspondence: ysakai22q13@gmail.com

'Department of Pediatrics, Graduate School of Medical Sciences, Kyushu University, 3-1-1 Maidashi, Higashi-ku, Fukuoka 812-8582, Japan

Full list of author information is available at the end of the article
}

[3]. In accordance with the expression of $L A M B 2$ at the neuromuscular junctions, patients with PS show severe muscular hypotonia and developmental delay [2].

The majority of patients with PS die of renal failure within the first year of life. Despite this vital symptom, recent evidence has shown that the implementation of renal replazcement therapy in infancy is effective for extending life span $[4,5]$. On the other hand, the full clinical spectrum of the long-term survivors and the time course of neuromuscular complications remain elusive. In this report, we present the case of a patient with PS

C C The Author(s). 2020 Open Access This article is licensed under a Creative Commons Attribution 4.0 International License, which permits use, sharing, adaptation, distribution and reproduction in any medium or format, as long as you give appropriate credit to the original author(s) and the source, provide a link to the Creative Commons licence, and indicate if changes were made. The images or other third party material in this article are included in the article's Creative Commons licence, unless indicated otherwise in a credit line to the material. If material is not included in the article's Creative Commons licence and your intended use is not permitted by statutory regulation or exceeds the permitted use, you will need to obtain permission directly from the copyright holder. To view a copy of this licence, visit http://creativecommons.org/licenses/by/4.0/ The Creative Commons Public Domain Dedication waiver (http://creativecommons.org/publicdomain/zero/1.0/) applies to the data made available in this article, unless otherwise stated in a credit line to the data. 
carrying a compound heterozygous mutation in LAMB2. The patient showed progressive gastrointestinal as well as dysautomomic features as novel complications of PS.

\section{Case presentation}

The patient, a 12-month-old boy was the third child of non-consanguineous, healthy parents. He had healthy sisters of 5 and 4 years of age. The patient was born via vaginal delivery without asphyxia at 35 weeks of gestational age. The patient's birth weight, length and head circumference were $2342 \mathrm{~g}$ (0.0 SD), $45.2 \mathrm{~cm}$ (0.0 SD) and $33.4 \mathrm{~cm}(1.2 \mathrm{SD})$, respectively. The placental weight was $850 \mathrm{~g}$. Oliguria continued from birth, and the serum creatinine level was elevated to $2.63 \mathrm{mg} / \mathrm{dl}$ on the 5 th day of age. Congenital nephrotic syndrome was suspected based on the detection of hypoalbuminemia (2.1 $\mathrm{g} / \mathrm{dl}$ ) and proteinuria (3+ on dipstick).

He was transferred to our hospital at 6 days of age. On admission, his consciousness was alert and his vital signs were stable: respiratory rate $37 / \mathrm{min}$, heart rate $149 / \mathrm{min}$, and blood pressure $84 / 54 \mathrm{mmHg}$. Bilateral microcoria and nystagmus were evident. The body posture and voluntary movements were normal. The muscular tone appeared normal. Deep tendon reflex was brisk. Laboratory tests confirmed that the urine protein/creatinine ratio was increased to $95.1 \mathrm{mg} / \mathrm{mg}$ Cre. Renal ultrasonography showed hyperechoic signals in both kidneys with unclear cortico-medullary structures. Continuous hemodiafiltration was introduced at 7 days of age, which was then replaced by peritoneal dialysis from 12 days of age. He became anuric during the course and continued peritoneal dialysis afterwards. With these renal replacement therapies, he survived the first 12 months of life.

Intestinal malrotation was diagnosed after the patient began experiencing recurrent vomiting started at 6 months of age (Fig. 1a). The volvulus was successfully relieved by surgery. However, the vomiting signs persisted beyond the surgical repair due to the presence of another digestive dysfunction, gastroesophageal reflux (Fig. 1b). Although duodenal tube feeding was introduced, only limited amounts of nutrition could be provided, which proved insufficient to achieve weight gain during the 12-month follow-up period. Thus, tulobuterol $(0.2 \mathrm{mg} /$ day $)$ was given orally from 12 months. The patient's vomiting disappeared immediately after tulobuterol treatment, and his weight continued to increase until the time of writing this report. In the last month, it reached $5300 \mathrm{~g}(+300 \mathrm{~g})$. Patients on peritoneal dialysis are also known to develop thyroid dysfunctions [6]. We verified that serum thyroid stimulating hormone $(2.70 \mu \mathrm{IU} / \mathrm{mL})$ and free thyroxine $(1.48 \mathrm{ng} / \mathrm{dL})$ levels remained unaltered. We thus did not interpret hyper- or hypothyroidism as a primary cause of his gastrointestinal problems.

Serial neurological assessments demonstrated that he had started gazing at and pursuing the objects from 2 months of age. However, generalized muscle weakness and hypotonia became prominent from 3 months of age. Presently at 12 months of age, his developmental quotient score is considered to be less than 20 (equivalent to the score of an infant of 2-3 months of age). He has been unable to control his neck, roll over, or sit unaided. Electrocardiography showed normal sinus rhythm and a normal axis with a corrected QT interval of $356 \mathrm{msec}$. The coefficient of variation in electrocardiographic R-R intervals (13.5\%) remained within the normal range. Echocardiography demonstrated the balance of the 4 chambers and a normal left-heart function with an ejection fraction of $82.9 \%$.

The clinical features of congenital nephrotic syndrome with microcoria prompted us to conduct the genetic testing for the diagnosis of PS. Whole-exome sequencing followed by the Sanger method showed that the patient harbored a compound heterozygous mutations in exon 14 (NM_002292.3:c.1648C > T:p.Arg550X) and exon 27 (NM_002292.3:c.4519C > T:p.Glu1507X) in the LAMB2 gene (Fig. 2a). An inheritance analysis demonstrated that

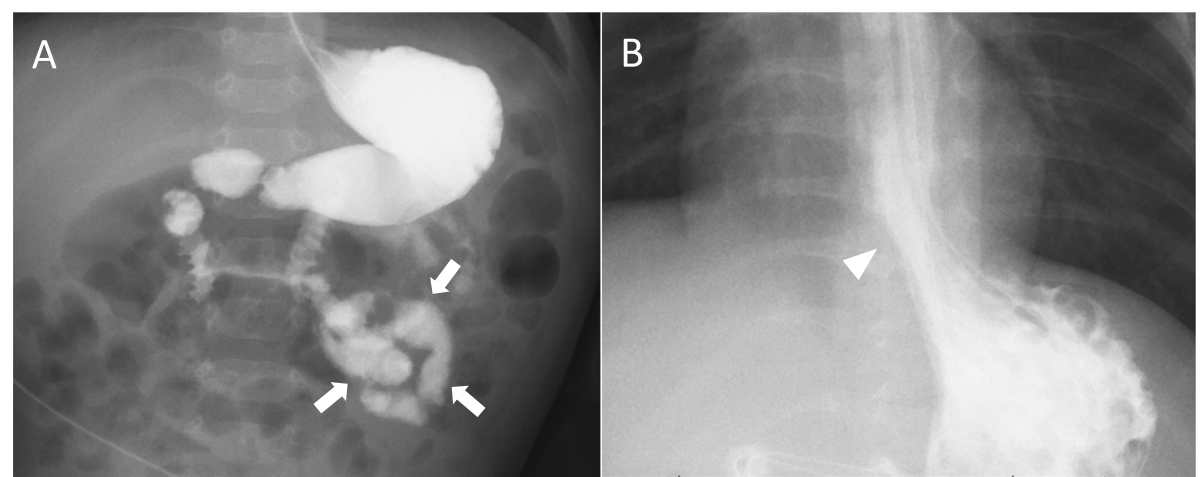

Fig. 1 Gastrointestinal phenotypes associated with Pierson syndrome. a An upper gastrointestinal contrast study depicting the intestinal malrotation. Arrows indicate the "corkscrew sign" of the proximal jejunum. b A radiographic contrast image depicting the gatroesophageal reflux (arrow head) 


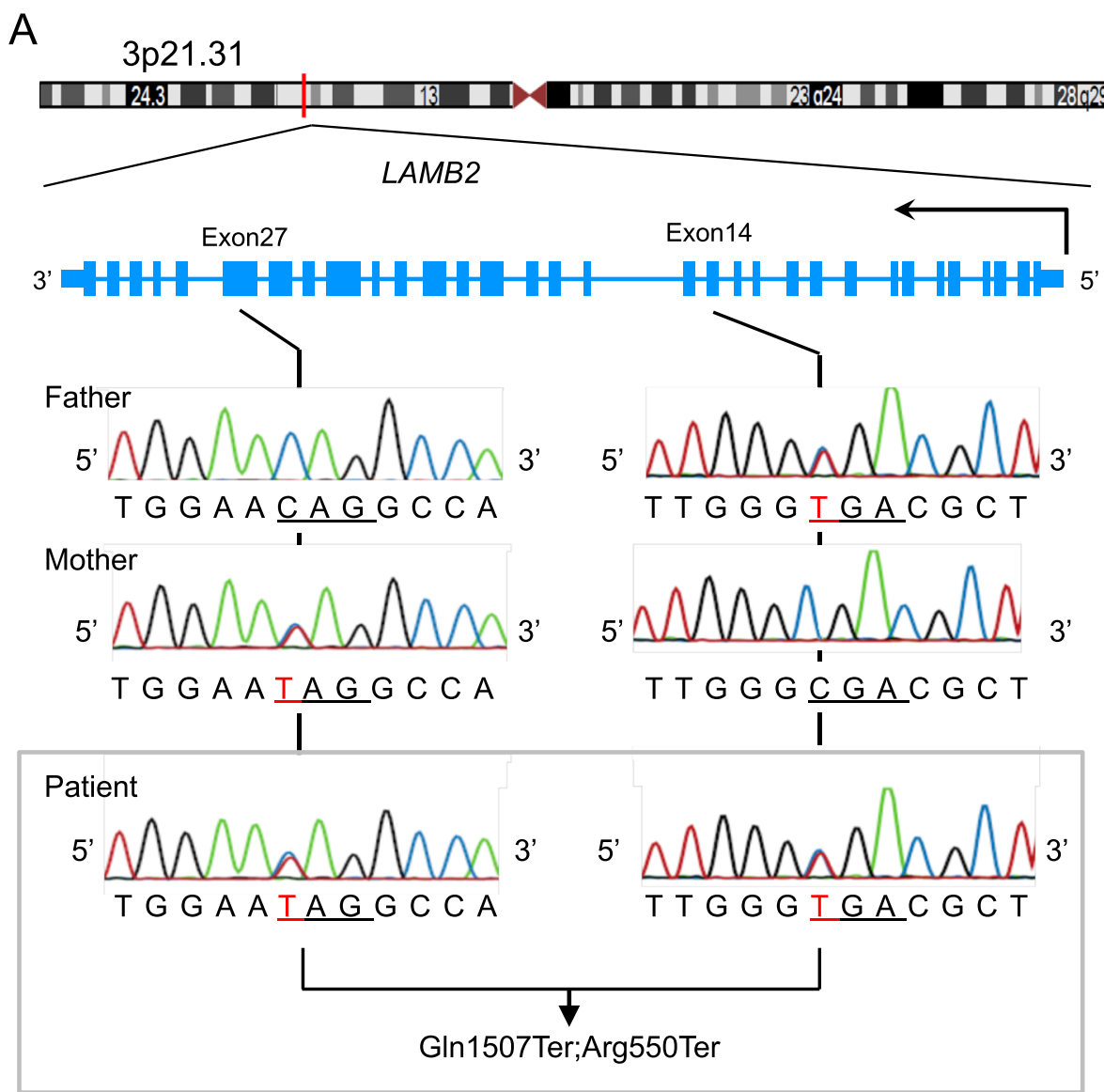

B

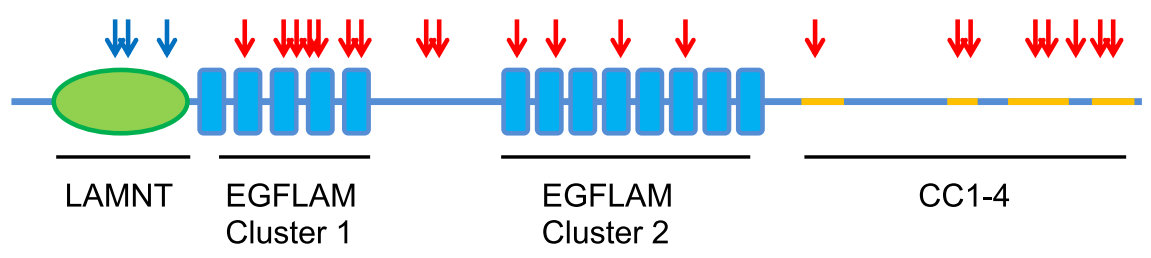

\section{$\downarrow$ Missense and in-frame deletions $\quad \downarrow$ Nonsense and frame-shifts}

Fig. 2 LAMB2 mutations in this and previously reported cases of Pierson syndrome. a Sequencing chromatograms of the father, mother and the patient are shown. The $5^{\prime}$ to $3^{\prime}$ ends of the transcripts are indicated in combination with each diagram. Vertical arrows indicate the position of mutations; exon14 (c.1648C > T:p.Arg550X) and exon 27 (c.4519C > T:p.Glu1507X), and mutated codons are underlined. b Pathogenic mutations associated with the neuromuscular symptoms of PS are mapped to the functional domains of Laminin $\beta 2$ protein. Red arrows: nonsense and frame-shift mutations; Black arrows: missense mutations and in-frame deletions. LAMNT, laminin N-terminal globular domain; EGFLAM, laminin EGF-like modules; CC, laminin coiled coil domain

his father and mother carried the heterozygous mutations in exon 14 (NM_002292.3:c.4519C > T:p.Glu1507X) and exon 27 (NM_002292.3:c.4519C > T:p.Glu1507X), respectively. Thus, the patient was genetically diagnosed with PS.

We found 19 patients with PS, who have been reported to manifest severe neuro-muscular problems (Table 1). All of these patients showed neurological signs of hypotonia or developmental delay, whereas their onset or time course was not described in detail. Eight patients survived 12 months after birth, and 7 of them received renal replacement therapy (dialysis or kidney transplantation) in early infancy. Among them, only one patient was reported to show gastrointestinal problems. No detailed information was available on the gastrointestinal features of the other long-term survivors. 


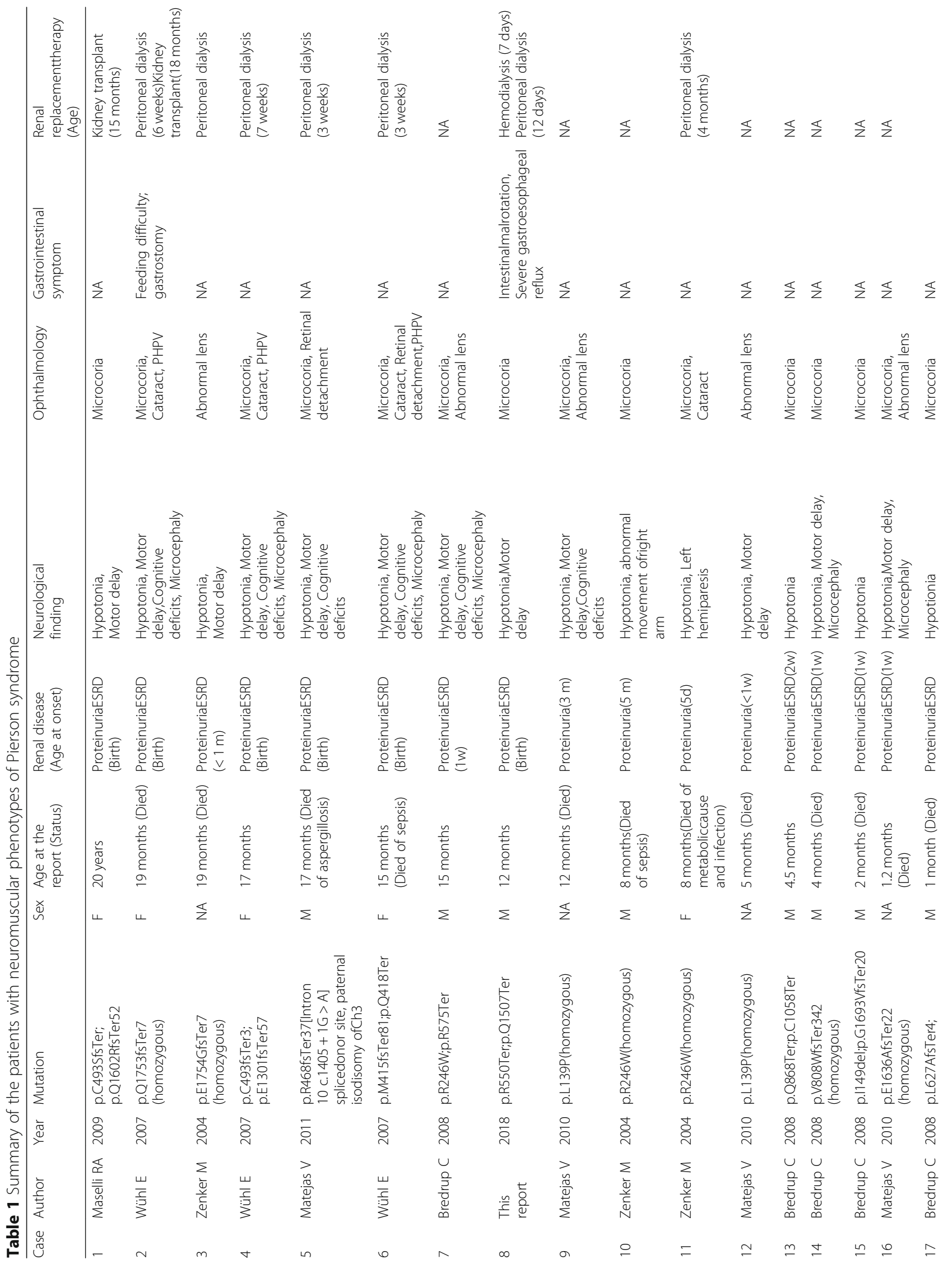




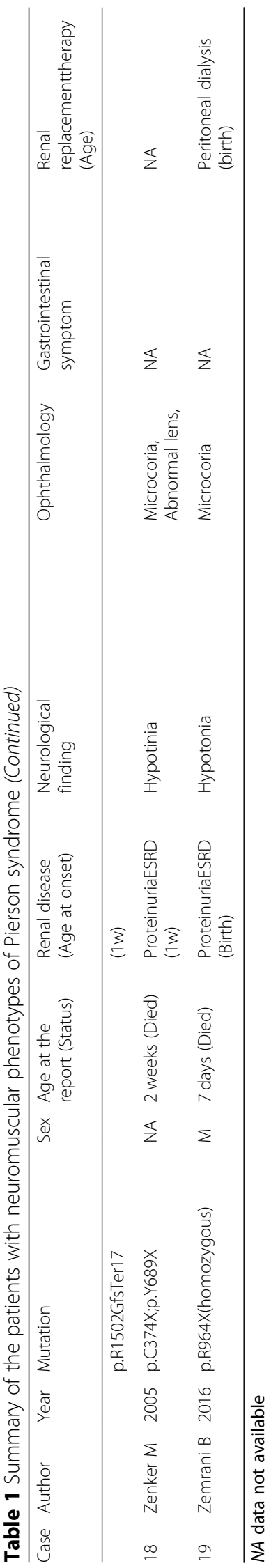


Mutation maps of these 19 patients are graphically summarized in Fig. 2b. Notably, all truncating mutations were located outside the laminin N-terminal (LAMNT) globular domain and the missense or in-frame deletions were mapped to the LAMNT domain. This result indicated both the pathogenic impacts of the disrupted LAMB2 protein and the functional significance of the LAMNT domain.

\section{Discussion and conclusions}

We reported the case of a patient with PS carrying truncating mutations in $L A M B 2$. This report extended the phenotypic spectrum of PS by clarifying that gastrointestinal dysfunction emerged after the first few months of life. Earlier studies have demonstrated the clinical course of patients with PS, and clarified their pathological bases in both human subjects and animal models. In agreement with the clinical course of the present case, a previous report supports the notion that neuromuscular deficits may emerge and progress in early infancy [5, 79]. In animal studies, the morphological analyses revealed that the number of presynaptic vesicles and the size of nerve termini at the neuro-muscular junctions (NMJ) did not differ between Lamb2-nulli mice and their littermates during the first few days of life [10]. Notably, however, prominent differences emerged after postnatal day 7 [11]. These findings suggest that laminin $\beta 2$ is important for postnatal maturation of NMJ in both humans and mice during the first few weeks after birth. In this regard, the absence of neurological findings at birth does not imply that patients with PS will show mild symptoms in late infancy.

In addition to the detailed time course of the neurological findings, this report first disclosed that PS patients may develop intestinal malrotation and gastroesophageal reflux. Notably, we found a report presenting the case of a patient with PS, who survived the neonatal period and underwent gastrostomy due to poor feeding [12]. Experimental data also showed that laminin $\beta 2$ is expressed in upper gastrointestinal tract [13]. In some PS patients, neuromuscular symptoms showed initial improvement with the administration of oral ephedrine [5]. The mode of action of $\beta$-stimulants is not fully understood; however, they increase the release of quanta of acetylcholine and reduce the acetylcholine receptor open time in vitro $[14,15]$. Tulobuterol possibly acts at the autonomic nerve termini, which might have contributed to the amelioration of the gastrointestinal symptoms of this patient. These findings suggest that the gastrointestinal dysfunction is not a rare complication in patients with PS.

Intestinal malrotation represents a heterogeneous group of disorders, and the genetic backgrounds for this complex condition remain to be explored [16].
Nonetheless, 4 main factors have been proposed to explain its underlying mechanisms: 1) abnormal left-right patterning, 2) an aberrant dorsal mesentery, 3) dysfunction of the intestine itself, or 4) dysfunction of other abdominal contents [17]. Given the expression of $L A M B 2$ in the intestine, the third mechanism is likely to support the pathogenic link between PS and the intestinal malrotation in the present case. The correlations of the timeframe of the appearance of neurological signs and the intestinal malrotations will be explored more extensively in future studies with additional cases with PS.

This is the first report to delineate the time course of neurological signs and gastrointestinal involvements in a patient with PS, as well as the extended spectrum of the clinical phenotype.

\section{Abbreviations}

PS: Pierson syndrome; LAMNT: Laminin N-terminal; NMJ: neuro-muscular junctions

\section{Acknowledgements}

We thank all the members of our departments at Kyushu University Hospital for their helpful discussions and comments on this manuscript.

\section{Authors' contributions}

KN1, MK, YS and SO2 conceptualized this study, assessed all of the clinical data, and wrote the manuscript. SM and KN2 performed sequencing. NK and YM provided critical care. MT, YS, MA, ST and K-HS assessed the neurological and ophthalmological findings. SO1 and TT managed the surgical procedures and gastrointestinal problems. All authors read and approved the final version of the manuscript and ensure this is the case. KN1 corresponds to Kei Nishiyama, and KN2 to Kandai Nozu.

\section{Funding}

This work was supported by the JSPS KAKENHI grant numbers JP17K16301, JP17K17334 and JP19K08281 in the design of the study, collection, interpretation and analysis of data; a Health and Labour Sciences Research Grant on Evidence-based Early Diagnosis and Treatment Strategies for Neuroimmunological Diseases from the Ministry of Health, Labour and Welfare of Japan for writing the manuscript and the design of this study; Life Science Foundation of Japan, Takeda Science Foundation, The Mother and Child Health Foundation, The Japan Epilepsy Research Foundation, and Kawano Masanori Memorial Public Interest Incorporated Foundation for Promotion of Pediatrics in writing the manuscript.

\section{Availability of data and materials}

All data are available in this manuscript and supplementary information. The datasets generated during the current study are available at the ClinVar (www.ncbi.nlm.nih.gov/clinvar/).

\section{Ethics approval and consent to participate}

Written informed consent to participate was obtained from the parents of the patients. This study was approved by the institutional review board at Kyushu University (\#461-00). This study was conducted in compliance with the institutional guideline for clinical studies.

\section{Consent for publication}

Written informed consent was obtained from the patient's parents for the publication of this case report and any accompanying images. A copy of the written consent is available for review by the Editor of this journal.

\section{Competing interests}

The authors declare that they have no competing interests.

\section{Author details}

'Department of Pediatrics, Graduate School of Medical Sciences, Kyushu University, 3-1-1 Maidashi, Higashi-ku, Fukuoka 812-8582, Japan. ${ }^{2}$ Department 
of Ophthalmology, Graduate School of Medical Sciences, Kyushu University, Fukuoka, Japan. ${ }^{3}$ Department of Pediatric Surgery, Graduate School of Medical Sciences, Kyushu University, Fukuoka, Japan. ${ }^{4}$ Department of Pediatrics, Kobe University Graduate School of Medicine, Kobe, Japan ${ }^{5}$ Emergency and Critical Care Center, Kyushu University Hospital, Fukuoka, Japan.

Received: 21 April 2019 Accepted: 1 April 2020

Published online: 15 April 2020

\section{References}

1. Zenker M, Tralau T, Lennert T, Pitz S, Mark K, Madlon H, Dötsch J, Reis A, Müntefering $H$, Neumann LM. Congenital nephrosis, mesangial sclerosis, and distinct eye abnormalities with microcoria: an autosomal recessive syndrome. Am J Med Genet A. 2004a;130A(2):138-45. https://doi.org/10. 1002/ajmg.a.30310

2. Zenker, M., Aigner, T., Wendler, O., Tralau, T., Müntefering, H., Fenski, R., Pitz, S., Schumacher, V., Royer-Pokora, B., Wühl, E., Cochat, P., Bouvier, R., Kraus, C., Mark, K., Madlon, H., Dötsch, J., Rascher, W., Maruniak-Chudek, I., Lennert, T., Neumann, L.M., Reis, A., 2004b. Human laminin beta2 deficiency causes congenital nephrosis with mesangial sclerosis and distinct eye abnormalities. Hum Mol Genet. 13(21), 2625-32. doi: https://doi.org/10.1093/ hmg/ddh284.

3. Miner JH, Patton BL. Laminin-11. Int J Biochem Cell Biol. 1999:31(8):811-6.

4. Guler S, Cimen S, Acott P, Whelan K, Molinari M. Kidney transplantation in a child with Pierson syndrome. Pediatr Transplant. 2017;21(8). https://doi.org/ 10.1111/petr.13076.

5. Maselli RA, Ng JJ, Anderson JA, Cagney O, Arredondo J, Williams C, Wessel HB, Abdel-Hamid H, Wollmann RL. Mutations in LAMB2 causing a severe form of synaptic congenital myasthenic syndrome. J Med Genet. 2009;46(3): 203-8. https://doi.org/10.1136/jmg.2008.063693.

6. Meuwese CL, Carrero JJ, Cabezas-Rodríguez I, Heimburger O, Barany P, Lindholm B, Qureshi AR, Ripsweden J, Dekker FW, Stenvinkel P. Nonthyroidal illness: a risk factor for coronary calcification and arterial stiffness in patients undergoing peritoneal dialysis? J Intern Med. 2013;274: 584-93.

7. Wühl E, Kogan J, Zurowska A, Matejas V, Vandevoorde RG, Aigner T, Wendler O, Lesniewska I, Bouvier R, Reis A, Weis J, Cochat P, Zenker M. Neurodevelopmental deficits in Pierson (microcoria-congenital nephrosis) syndrome. Am J Med Genet A. 2007;143(4):311-9 10.1002/ajmg.a.31564.

8. Matejas V, Muscheites J, Wigger M, Kreutzer HJ, Nizze H, Zenker M. Paternal isodisomy of chromosome 3 unmasked by autosomal recessive microcoriacongenital nephrosis syndrome (Pierson syndrome) in a child with no other phenotypic abnormalities. Am J Med Genet A. 2011;155A(10):2601-4. https://doi.org/10.1002/ajmg.a.34214.

9. Zemrani B, Cachat F, Bonny O, Giannoni E, Durig J, Fellmann F, Chehade H. A novel LAMB2 gene mutation associated with a severe phenotype in a neonate with Pierson syndrome. Eur J Med Res. 2016;21:19. https://doi.org/ 10.1186/s40001-016-0215-Z.

10. Fox MA, Sanes JR, Borza DB, Eswarakumar VP, Fässler R, Hudson BG, John SW, Ninomiya Y, Pedchenko V, Pfaff SL, Rheault MN, Sado Y, Segal Y, Werle MJ, Umemori H. Distinct target-derived signals organize formation, maturation, and maintenance of motor nerve terminals. Cell. 2007;129(1): 179-93. https://doi.org/10.1016/j.cell.2007.02.035.

11. Nishimune H, Sanes JR, Carlson SS. A synaptic laminin-calcium channel interaction organizes active zones in motor nerve terminals. Nature. 2004; 432(7017):580-7. https://doi.org/10.1038/nature03112.

12. Falix FA, Bennebroek CA, van der Zwaag B, Lapid-Gortzak R, Florquin S, Oosterveld MJ. A novel mutation of laminin $\beta 2$ (LAMB2) in two siblings with renal failure. Eur J Pediatr. 2017;176(4):515-9. https://doi.org/10.1007/s00431017-2871-6.

13. Dave U, Thursz MR, Ebrahim HY, Burke MM, Townsend ER, Walker MM. Distribution of laminins in the basement membranes of the upper gastrointestinal tract and Barrett's oesophagus. J Pathol. 2004;202(3):299304. https://doi.org/10.1002/path.1526.

14. Sieb JP, Engel AG. Ephedrine: effects on neuromuscular transmission. Brain Res. 1993;623:167-71. https://doi.org/10.1016/0006-8993(93)90025-I.

15. Milone M, Engel AG. Block of the endplate acetylcholine receptor channel by the sympathomimetic agents ephedrine, pseudoephedrine, and albuterol. Brain Res. 1996;74:346-52. https://doi.org/10.1016/S00068993(96)00894-3.
16. Stankiewicz P, Sen P, Bhatt SS, Storer M, Xia Z, Bejjani BA, Ou Z, Wiszniewska J, Driscoll DJ, Maisenbacher MK, Bolivar J, Bauer M, Zackai EH, McDonaldMcGinn D, Nowaczyk MM, Murray M, Hustead V, Mascotti K, Schultz R, Hallam L, McRae D, Nicholson AG, Newbury R, Durham-O'Donnell J, Knight G, Kini U, Shaikh TH, Martin V, Tyreman M, Simonic I, Willatt L, Paterson J, Mehta S, Rajan D, Fitzgerald T, Gribble S, Prigmore E, Patel A, Shaffer LG, Carter NP, Cheung SW, Langston C, Shaw-Smith C. Genomic and genic deletions of the FOX gene cluster on $16 \mathrm{q} 24.1$ and inactivating mutations of FOXF1 cause alveolar capillary dysplasia and other malformations. Am J Hum Genet. 2009;84(6):780-91. https://doi.org/10.1016/j.ajhg.2009.05.005.

17. Martin V, Shaw-Smith C. Review of genetic factors in intestinal malrotation. Pediatr Surg Int. 2010;26(8):769-81. https://doi.org/10.1007/s00383-010-2622-5.

\section{Publisher's Note}

Springer Nature remains neutral with regard to jurisdictional claims in published maps and institutional affiliations.
Ready to submit your research? Choose BMC and benefit from:

- fast, convenient online submission

- thorough peer review by experienced researchers in your field

- rapid publication on acceptance

- support for research data, including large and complex data types

- gold Open Access which fosters wider collaboration and increased citations

- maximum visibility for your research: over $100 \mathrm{M}$ website views per year

At $\mathrm{BMC}$, research is always in progress.

Learn more biomedcentral.com/submissions 